\title{
A educação fora do espaço prisional: um olhar dos professores do curso popular Cultura da Paz
}

\author{
La educación fuera del espacio prisional: una mirada de los profesores del \\ curso popular Cultura de la Paz
}

\author{
Education outside prisons: a glimpse of the teachers of the popular course \\ Culture of Peace
}

\author{
Peterson Fernando Kepps da Silva ${ }^{1}$ \\ Cristiane da Cunha Alves ${ }^{2}$ \\ Samanta Costa Calcagno ${ }^{3}$
}

\begin{abstract}
Resumo
O aumento da população presidiária no Brasil é alarmante, em números totais o país ocupa a terceira colocação com maior população presidiária. Além disso, a conjuntura precária e deficiente que o sistema prisional brasileiro apresenta, como superlotação, que unida à estrutura precária das instalações e a falta de profissionais no espaço prisional, dificultam a ressocialização dos indivíduos. Em meio a este cenário, emerge o curso popular pré-universitário Cultura da Paz. O curso é vinculado a um projeto de extensão da Universidade Federal do Rio Grande (FURG). Este trabalho visa investigar as percepções dos educadores que atuaram nos anos de 2016 e 2017 no curso Educacional Cultura da Paz. Para tanto, realizamos um questionário com três perguntas: 1) Como foi sua experiência enquanto Educador do contexto Cultura da Paz?; 2) Descreva alguma experiência, momento e/ou atividade, junto aos estudantes, que lhe marcou; 3) Por que você escolheu dar aula no contexto Cultura da Paz?. Cinco professores responderam ao questionário. Objetivamos tencionar as discussões no que concerne à educação escolar no sistema prisional e o quanto pode ser produtiva estas ações para a construção de uma sociedade mais igualitária. Informamos que o questionário foi aplicado no segundo semestre de $2018 \mathrm{e}$, posteriormente analisado de acordo com cada questão. Podemos concluir que os educadores têm preocupação, dedicação e compreensão de que a educação é uma possibilidade de crescimento pessoal, e social das pessoas que estão cumprindo pena prisional. Dessa forma, as aulas do curso Cultura da Paz proporcionou um amadurecimento como ser humano e como profissional para os educadores. As trocas entre educadores e estudantes foram intensas demonstrando o quão positivo foi o envolvimento desses com as atividades propostas. E por fim, os momentos em coletivo proporcionaram um espaço para o diálogo e para que expusessem sua bagagem pessoal sobre os temas trabalhados.
\end{abstract}

Palavras-Chave: Professores; Cultura da paz; Pessoas presas; Educação

\section{Resumen}

El aumento de la población presidiaria en Brasil es alarmante, en números totales el país ocupa la tercera colocación con mayor población presidiaria. Además, la coyuntura precaria y deficiente que el sistema prisional brasileño presenta, como superlotación, que unida a la estructura precaria de las instalaciones y la falta de profesionales en el espacio prisional, dificultan la resocialización de los individuos. En medio de este escenario,

\footnotetext{
${ }^{1}$ Mestre em Educação em Ciências Ciências - Programa de Pós-Graduação em Educação em Ciências (PPGEC), Rio Grande, RS, Brasil, keppspeterson@gmail.com

${ }^{2}$ Mestre em Educação em Ciências - Programa de Pós-Graduação em Educação em Ciências (PPGEC), Rio Grande, RS, Brasil, crisalves1917@ hotmail.com.

${ }^{3}$ Mestranda do Programa de Pós-Graduação em Educação em Ciências: Química da Vida e Saúde (PPGEC), Rio Grande, RS, Brasil, samantacalcagno@hotmail.com
} 
emerge el curso popular preuniversitario Cultura de la Paz. El curso, vinculado a un proyecto de extensión de la Universidad Federal del Río Grande-FURG. El presente trabajo pretende investigar las percepciones de los educadores que actuaron en los años 2016 y 2017 en el curso Educativo Cultura de la Paz. Para ello, realizamos un cuestionario con tres preguntas: 1) ¿Cómo fue su experiencia como Educador del contexto Cultura de la Paz ?; 2) Describa alguna experiencia, momento y / o actividad, junto a los estudiantes, que le marcó; 3) ¿Por qué eligió dar clase en el contexto Cultura de la Paz ?. Cinco profesores respondieron al cuestionario. Objetivamos tener las discusiones en lo que concierne a la educación escolar en el sistema penitenciario y cuánto pueden ser productivas estas acciones para la construcción de una sociedad más igualitaria. Informamos que el cuestionario fue aplicado en el segundo semestre de 2018 y, posteriormente analizado de acuerdo con cada cuestión. Podemos concluir que los educadores tienen preocupación, dedicación y comprensión de que la educación es una posibilidad de crecimiento personal, y social de las personas que están cumpliendo pena prisión. De esta forma, las clases del curso Cultura de la Paz proporcionaron una maduración como ser humano y como profesional para los educadores. Los intercambios entre educadores y estudiantes fueron intensos demostrando cuán positivo fue la participación de ellos con las actividades propuestas. Y por fin, los momentos en colectivo proporcionaron un espacio para el diálogo y para que expusieran su equipaje personal sobre los temas trabajados.

Palabras clave: Profesores; Cultura de la paz; Personas presas; educación.

\begin{abstract}
The increase in the inmate population in Brazil is alarming, in total numbers the country occupies the third place with the largest prison population. In addition, the precarious and deficient conditions that the Brazilian prison system presents, such as overcrowding, coupled with the precarious structure of the facilities and the lack of professionals in prison space, make it difficult for the individuals to be resocialized. The course, linked to an extension project of the Federal University of Rio Grande-FURG, had as one of the main objectives to corroborate for education, possible entry into the Teaching Higher education and, consequently, social reintegration. The present work aims to investigate the perceptions of the educators who acted in the years of 2016 and 2017 in the Educational Culture of Peace course. For this purpose, we carried out a questionnaire with three questions, namely: 1) How was his experience as Educator of the context Culture of Peace ?; 2) Describe some experience, moment and / or activity, with the students, that marked you; 3) Why did you choose to teach in the Culture of Peace context? Five teachers answered the questionnaire. We objected to the questions, to discuss the discussions regarding school education in the prison system and how productive these actions could be for building a more egalitarian society. We inform that the questionnaire was applied in the second half of 2018 and then analyzed according to each of the questions. Through the analysis we have made, we can conclude that educators have a concern, dedication and understanding that education is a possibility for the personal and social growth of people who are serving prison sentences. In this way, the classes for the students of the Culture of Peace course provided a maturity as a human being and as a professional for educators. The exchanges between educators and students were intense demonstrating how positive the involvement of these with the proposed activities was. And finally, the moments in groups provided a space for dialogue and to expose their personal baggage on the topics worked.
\end{abstract}

Keywords: Teachers; Culture of peace; People arrested; Education

\title{
1. Introdução
}

Os altos índices da população presidiária no Brasil são alarmantes, os dados do Levantamento Nacional de Informações Penitenciárias - INFOPEN (2017) que foram divulgados pelo Departamento Penitenciário Nacional - DEPEN (2017), do Ministério da Justiça, apontam que em Dezembro de 2014, o total de apenados era de 622.202. Em Junho de 2016, o total de pessoas presas no Brasil era de 726.712. Em menos de dois anos houve um acréscimo de 104 mil pessoas presas. Deste total, 30\% da população penitenciária é composta por jovens entre 18 e 24 anos majoritariamente negros (INFOPEN, 2017). 
A população prisional brasileira, em números - incluindo pessoas do gênero feminino e masculino - ocupa a quarta colocação com maior população presidiária (INFOPEN, 2017). Todos esses dados evidenciam a conjuntura precária e deficiente que o sistema prisional brasileiro se apresenta. O excesso populacional ocasiona a superlotação, que unida à estrutura precária das instalações, a falta de profissionais no espaço prisional, dificultam a ressocialização dos indivíduos.

Existem diferentes prerrogativas referentes à reinserção dos indivíduos presos, dentre elas, o acesso à educação. Segundo a Lei de Execução Penal (LEP, 1984) é dever do Estado oferecer as pessoas presas assistência educacional, que compreende a instrução escolar e a formação profissional. Sendo o Ensino Fundamental obrigatório, os sistemas de ensino prisional acabam oferecendo, por vezes, cursos supletivos de educação de jovens e adultos.

O INFOPEN (2016), no que se refere aos dados sobre escolarização da população prisional, divulgou um levantamento feito com $70 \%$ (482.645 pessoas) das pessoas que estão presas, e demonstrou que 51\% delas possui Ensino Fundamental incompleto.

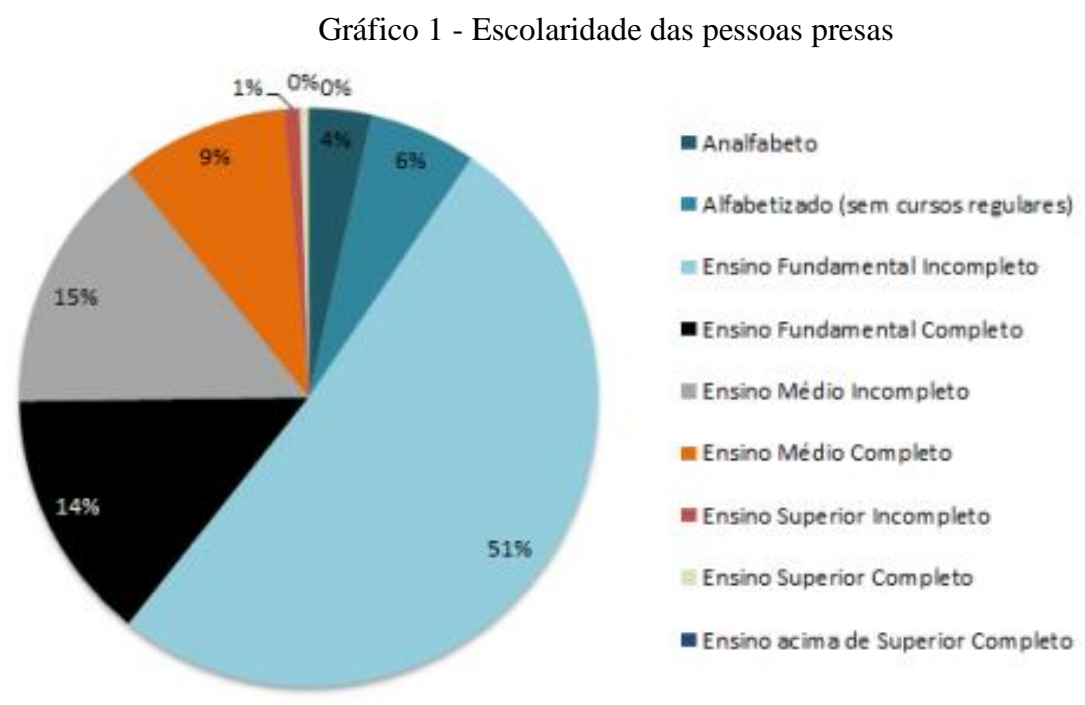

Fonte: INFOPEN (2016)

Tais dados estão em concordância com o Levantamento do Conselho Nacional de Educação, no qual expressa que a maioria das pessoas presas não concluiu o Ensino Fundamental. Isso pode ser traduzido, principalmente, em homens com idades entre 18 e 34 anos (BRASIL, 2012).

Atentamos-nos ao não determinismo, contudo, dentro de uma tríade entre classe social, raça e criminalidade se evidencia que a baixa escolaridade está associada às condições 
sociais mais desfavorecidas. Além disso, vivências em contextos de existência que apresentam menos oportunidades de desenvolvimento pessoal, social e humano, e também com maior vulnerabilidade social, estão associados ao perfil presidiário do Brasil.

A Constituição Federal de 1988 prevê a educação como um direito de todos. A educação, então, passaria a ser promovida e incentivada de forma que conte não somente com a colaboração do Estado e da família, mas de toda a sociedade - visando, com isso, o pleno desenvolvimento da pessoa.

Com base nessas prerrogativas da Constituição Federal, e de acordo com o que foi exposto anteriormente sobre o contexto educacional da população prisional, podemos dizer que o Estado falhou com essas pessoas, ao não garantir o direito ao acesso e permanência desses indivíduos sobre a sua escolarização. No entanto, ainda que falhas sejam cometidas pelo Estado algumas assertivas ocorrem. Proposições como a Educação de Jovens e Adultos (EJA), têm contribuído para a educação das pessoas presas (AGUIAR, 2009).

Com o intuito de corroborar para a educação, e consequentemente para a reinserção das pessoas presas na sociedade, é que emerge durante os anos de 2016 e 2017 o projeto de extensão Cultura da Paz. Este projeto foi voltado, especificamente, para apenados do regime aberto e semiaberto da Penitenciária Estadual do Rio Grande (PERG). Nesse sentido, o presente trabalho visa investigar as percepções dos educadores que atuaram no curso Educacional Cultura da Paz ao longo deste período.

\section{Considerações metodológicas}

Antes de discorrermos sobre os meios dos quais nos utilizamos para produzirmos nossos dados, é preciso circunscrever como se organizou e expressar os vínculos institucionais que ampararam o curso ao longo de seus dois anos de existência.

Construímos frases no passado quando nos referirmos ao curso porque o mesmo, no ano de 2018, teve suas atividades interrompidas. Ainda no início do referido ano, período no qual estávamos nos organizando enquanto coordenação pedagógica e professores para iniciarmos as aulas, um incêndio atingiu uma das dependências da PERG. O alojamento em que se deu o ocorrido abrigava presos do regime semiaberto, "modalidade" prisional na qual abrigava os apenados que já participaram e participariam do curso. Com a realidade que se instalou, tivemos de cancelar as atividades planejadas e o desenvolvimento das aulas.

O curso Educacional Popular Cultura da Paz, como já dito anteriormente, emergiu no início do ano de 2016 e suas atividades perduraram até o final do ano de 2017, com 
interrupção apenas em meses de férias, o que corresponde após as provas do Exame Nacional do Ensino Médio (ENEM).

O curso objetivava o ingresso dos estudantes na Universidade, por isso, poderia ser caracterizado como um pré-universitário. Entretanto, até o ano de 2016, a nota obtida no ENEM poderia ser utilizada não só para o ingresso no Ensino Superior, mas como instrumento de conclusão do Ensino Médio. Isso nos levou a ter, inicialmente, dois objetivos principais: contribuir com a conclusão da última etapa da educação básica; e o ingresso no Ensino Superior.

A proposta de conteúdos do curso estava alicerçada nas áreas de conhecimentos avaliadas no ENEM, a saber: 1) Ciências da Natureza e suas Tecnologias; 2) Ciências Humanas e suas Tecnologias; 3) Linguagens e Códigos; 4) Matemática; e 5) Redação. Para tanto, educadores voluntários desenvolviam disciplinas que atendessem essas áreas. A carga horária do curso era de segunda a sexta-feira, no turno da noite (entre $19 \mathrm{~h}$ e $22 \mathrm{~h}$ ), e acontecia nos espaços da Universidade Federal do Rio Grande (FURG).

A parceria se deu com a FURG por meio do PAIETS - Programa de Auxílio ao Ingresso nos Ensinos Técnico e Superior. O PAIETS, como a sigla já indica, é um programa de inclusão social que possui cursos de apoio educacional em diferentes bairros do município do Rio Grande e em outros da região sul do Rio Grande do Sul.

Além da questão de aprendizagem dos conteúdos, que se torna pertinente para um futuro ingresso no Ensino Superior ou conclusão do Ensino Médio, eram desenvolvidas atividades como oficinas pedagógicas, saídas de campo, e participação em eventos, já descritas em outro trabalho (SILVA e SCHWANTES, 2018). Essas atividades e ações visavam à criação de espaços menos rígidos e fixos; o dialogar com o interesse dos alunos; e a tessitura de propostas mais reflexivas que estimulassem a posição dos estudantes.

Sobre os educadores e a coordenação do curso, todos eram voluntários, estavam na graduação, pós-graduação e/ou eram profissionais já formados atuantes em suas áreas. Além disso, cabe destacar que existia uma parceria com a direção da penitenciária e com a equipe de assistência social, com as quais mantínhamos contato mais direto e resolvíamos todas as questões documentais como, por exemplo, a emissão das atas de presenças dos alunos diariamente.

Em síntese, o curso Cultura da Paz teve dois anos de atividades, seu plano pedagógico era construído de modo a contemplar às áreas de conhecimento avaliadas no ENEM, assim como contribuir, por meio de atividades e ações, com a inserção destes sujeitos no meio social. As aulas aconteciam nos prédios da FURG, a coordenação e professores eram 
voluntários, os estudantes estavam em regime semiaberto (por isso poderiam comparecer na Universidade), e a parceria com a direção da PERG era vital para sua existência.

Passada estas considerações que contextualizam e circunscrevem a maneira como se deu o curso Cultura da Paz, voltamo-nos para o meio de produção de dados. Torna-se importante lembrar que temos como objetivo investigar as percepções dos educadores que atuaram no curso. Para além de um possível referencial teórico que a palavra "percepção" possa se vincular, a tomamos apenas como um substantivo no qual expressa, neste caso, como os professores perceberam e/ou compreenderam o período em que estiveram no curso.

Realizamos, para atingir este propósito, um questionário no qual foi respondido virtualmente pelos professores que atuaram tanto no ano 2016 quanto 2017. O questionário foi construído através do Google Drive, na opção formulários. Escolhemos essa ferramenta, porque ela proporciona um fácil acesso aos dados e de maneira organizada podemos analisar cada resposta. Depois de construído o formulário, enviamos um link com as questões por meio de e-mail e/ou mensagens enviadas pelas redes sociais e convidamos estes professores a responderem o questionário. Informamos aos investigados que os dados serão utilizados apenas para fins acadêmicos e que suas informações pessoais como nome serão preservadas. Junto a isso, passamos o link para que os interessados em contribuir com a pesquisa pudessem acessar o questionário. Enviamos a um total de 10 (dez) professores e obtivemos resposta de 5 (cinco). O período em que o questionário online esteve aberto para os respondentes foi de 14 de Setembro até 10 de Outubro de 2018.

Solicitamos na primeira seção do questionário que os participantes se identificassem através de cinco aspectos, sendo eles: o nome do educador, ano de formação, disciplina que lecionou tempo que atuou no curso, e área de formação. Pedimos estas informações para conhecer o perfil dos sujeitos de pesquisa e, também, para que possamos compreender as diferentes visões e experiências.

Na segunda seção do questionário, realizamos as seguintes perguntas: 1) Por que você escolheu dar aula no curso Cultura da Paz?; 2) Como foi sua experiência enquanto "Educador"?; 3) Descreva alguma experiência, momento e/ou atividade junto aos estudantes que considere significativo.

De modo geral, estas perguntas podem nos indicar os motivos que levaram estes educadores a realizarem um trabalho voluntário no curso, bem como apontar as experiências que consideram significativas durante o período em que atuaram. Mapear estas questões pode nos permitir compreender quem são estes educadores, quais foram suas expectativas sobre o 
curso e no decorrer do tempo em que permaneceram desenvolvendo aulas no curso, quais são os momentos significativos sobre esse processo social em relação aos estudantes.

As respostas não passaram por alterações, foram colocadas na integra em quadros para melhor organizar as ideias e facilitar aos leitores a visualização das mesmas. Elas passaram, apenas, por pequenas correções em erros de digitação. Além de organizarmos as respostas em quadros, para análise, agrupamos as semelhantes a fim de tornar as discussões mais produtivas e profícuas.

Para não identificarmos os educadores, nos utilizamos da sigla E1, E2 e assim por diante. A letra "E” refere-se ao educador e o número é utilizado para distingui-los.

No próximo tópico, trazemos o olhar dos educadores e discutimos as intencionalidades destes sobre o exercício da docência no curso Educacional Cultura da Paz.

\section{Cultura da Paz: a educação prisional}

Ao todo, como já apresentamos no percurso metodológico, tivemos cinco educadores respondentes. Destes, quatro foram educadores da área das ciências da natureza (1 de Química; 2 de Biologia; e 1 de Física). Apenas um da área das linguagens, especificamente educador das disciplinas de redação e português. Com relação ao ano em que eles concluíram a graduação, temos respostas entre: 2013 e 2019. O que significa dizer que apenas um destes educadores respondentes ainda não concluiu a graduação e que tínhamos, no curso, educadores ainda em processo de formação acadêmica.

\begin{tabular}{|c|c|c|c|c|}
\hline $\begin{array}{l}\text { Nome do } \\
\text { educador }\end{array}$ & $\begin{array}{l}\text { Ano de } \\
\text { formação }\end{array}$ & $\begin{array}{l}\text { Disciplina que } \\
\text { lecionou }\end{array}$ & $\begin{array}{c}\text { Tempo que atuou no } \\
\text { curso }\end{array}$ & Área de formação \\
\hline E1 & 2016 & Biologia & 2 anos & Ciências Biológicas Licenciatura \\
\hline E2 & 2014 & Biologia & 2 anos & Ciências Biológicas Licenciatura \\
\hline E3 & 2013 & Português e Redação & 2 anos & Letras - Português \\
\hline E4 & 2019 & Química & 1 ciclo no ano de 2017 & Enfermagem e finalizando Física \\
\hline E5 & 2016 & Física & 1 ciclo no ano de 2017 & $\begin{array}{l}\text { Licenciatura em Ciências da } \\
\text { Natureza }\end{array}$ \\
\hline
\end{tabular}

Quadro 1 - Dados referentes ao perfil dos educadores do curso Cultura da Paz Fonte: Autores (2018)

Sobre a primeira pergunta do questionário: 1) "Por que você escolheu dar aula no curso Cultura da Paz?” organizamos as respostas no seguinte quadro: 
RELACult - Revista Latino-Americana de Estudos em Cultura e Sociedade

\begin{tabular}{|c|l|}
\hline Educador & \multicolumn{1}{|c|}{ Resposta } \\
\hline E1 & $\begin{array}{l}\text { Por acreditar que a educação pode ser instrumento de apoio aos sujeitos. Principalmente } \\
\text { quando se encontram em situações de marginalização e vulnerabilidade. }\end{array}$ \\
\hline E2 & $\begin{array}{l}\text { Por acreditar que as pessoas privadas de sua liberdade precisam de oportunidades. } \\
\text { Oportunidades de concluir os estudos, assim conseguir uma vaga de emprego e ter novas } \\
\text { perspectivas de vida. }\end{array}$ \\
\hline E3 & $\begin{array}{l}\text { Porque gosto de trabalhar com comunidades diversas, também considero de suma importância } \\
\text { oportunizar a todos entrada a uma universidade e acho interessante devolver o investimento que } \\
\text { o Estado me proporcionou. }\end{array}$ \\
\hline E4 & $\begin{array}{l}\text { Movido pelo o desejo de ajudar a transformar através da educação, pessoas socioculturalmente } \\
\text { e economicamente vulneráveis. Vontade de munir de conhecimentos libertadores aqueles } \\
\text { tolhidos de liberdade. }\end{array}$ \\
\hline E5 & $\begin{array}{l}\text { Eu me candidatei para dar aula no curso porque queria exercer a profissão de docente e achei o } \\
\text { curso como um meio de começar essa trajetória. }\end{array}$ \\
\hline
\end{tabular}

Quadro 2 - Respostas da questão 1

Fonte: Autores (2018)

Se observarmos as respostas organizadas no quadro 2, podemos perceber que os educadores E1 e E4 acreditam na educação como instrumento de apoio e mudança no meio social. Tanto E1 quanto E4 destacam, também, a vulnerabilidade em que se encontram estes sujeitos. Podemos articular isso com os próprios dados do INFOPEN (2016) e DEPEN (2017), já apresentados aqui, onde nos traz uma realidade em valores numéricos de jovens, majoritariamente negros e com baixa instrução escolar figurando nas celas do sistema carcerário brasileiro. Certamente não temos por interesse minimizar os crimes cometidos pelos apenados, tampouco relegar a eles papel de "vitimas". Entretanto, as respostas dos educadores nos fazem pensar nessa marginalização, histórica no Brasil, que cerceia o direito de muitos a uma vida digna com acesso a questões básicas como alimentação, saúde e educação.

Pode parecer chavão apontarmos questões como essas, mas não por isso deixaremos de utilizar espaços como este trabalho para atentar e, por que não, alertar mais pessoas sobre o estado de calamidade dos presídios e, principalmente, a relação estreita entre os sujeitos que lá estão com características como classe social, cor da pele e grau de escolaridade.

Os educadores E2 e E3 trazem a ideia de oportunizar aos apenados uma posição no mercado de trabalho e uma vaga no Ensino Superior, respectivamente. Além disso, eles esboçam sobre possibilitar aos estudantes novas perspectivas de vida e um retorno para a sociedade, o que indica que o E3 cursou sua graduação em Universidade pública. Neste sentido, é importante perceber o curso Educacional Cultura da Paz enquanto um trabalho social que faz parte de um programa maior, o PAIETS. Este programa está relacionado ao 
cumprimento da responsabilidade social que a FURG e os seus integrantes assumem com a comunidade.

Já sobre a segunda pergunta: 2) "Como foi sua experiência enquanto "Educador" no curso Cultura da Paz?" organizamos o quadro abaixo:

\begin{tabular}{|c|l|}
\hline Educador & \multicolumn{1}{c|}{ Resposta } \\
\hline E1 & $\begin{array}{l}\text { Ao longo dos dois anos tive uma experiência muito rica. Os estudantes eram interessados e } \\
\text { participativos. Alguns solicitavam materiais para mais estudo e leituras. Eles relatavam, por } \\
\text { exemplo, que aos finais de semana (quando tinham de ficar no presídio durante o dia) } \\
\text { aproveitavam para estudar os assuntos e conteúdos vistos no curso. Isso nos dá indícios do } \\
\text { quão envolvidos estes estudantes estavam, do quão motivador e estimulante pode ser o } \\
\text { processo educativo. }\end{array}$ \\
\hline E2 & $\begin{array}{l}\text { Posso dizer que, como educador, a troca de conhecimento foi muito positiva e que obtive um } \\
\text { crescimento pessoal com a experiência. }\end{array}$ \\
\hline E3 & $\begin{array}{l}\text { Maravilhosa! Aprendi muito com essa experiência, além de que pude levar para meus alunos } \\
\text { assuntos pertinentes que deram bons debates e escritas. Ter a oportunidade de trocar } \\
\text { experiências é uma forma de crescer tanto como ser humano em si como também profissional. }\end{array}$ \\
\hline E4 & $\begin{array}{l}\text { Foi extremamente enriquecedor em todos os aspectos. Me pôs a aperfeiçoar meu acolhimento } \\
\text { para com todos os educandos. }\end{array}$ \\
\hline E5 & $\begin{array}{l}\text { Bom, quando fui fazer a entrevista não sabia que os alunos eram os presos do semiaberto, mas } \\
\text { ao começar a desenvolver as aulas com eles me apaixonei pelo curso. Minha experiência com } \\
\text { eles foi super tranquila, eles sempre se envolveram nas atividades propostas e todas as vezes as } \\
\text { horas passavam rápido. }\end{array}$ \\
\hline
\end{tabular}

Quadro 3 - Respostas da questão 2

Fonte: Autores (2018)

O quadro 3, traz o olhar dos educadores do curso sobre suas experiências enquanto voluntários envoltos em uma nova realidade social. Podemos perceber no relado dos participantes E2, E3 e E4, que desenvolver as aulas para os alunos do curso Cultura da Paz proporcionou um amadurecimento como ser humano e como profissional. As trocas entre educadores e estudantes foram intensas demonstrando o quão positivo foi o envolvimento desses com as atividades propostas.

Se olharmos, todos os educadores investigados compartilham de uma experiência rica, positiva, tranquila ou maravilhosa, de acordo com as palavras utilizadas por eles. Cada um a seu modo expressa a satisfação em desenvolver e fazer parte deste trabalho. Atrelado a isso, podemos destacar os E2 e E3, os quais trazem a ideia de crescimento pessoal. Independentemente do que esse termo pode representar para cada um, podemos interpretá-lo, a partir do contexto das respostas destes investigados, como um período significativo, de aprendizagens produtivas construídas ao longo do processo de atuação no curso.

Os educadores E1 e E5, destacam e descrevem como foi o processo de envolvimento dos educandos durante as aulas. Podemos inferir a partir das respostas que eles construíram 
uma amizade, ou uma ligação entre educador-educando. Isso nos indica, de certo modo, que o curso estava para além de replicação ou discussão apenas dos conteúdos, tendo em vista que, ainda segundo estes educadores investigados, ocorreu um processo de aproximação com os educandos. Nesse sentido, Freire (2007) nos traz a importância do diálogo entre professor e aluno:

[...] o diálogo é uma exigência existencial. E, se ele é o encontro em que se solidarizam o refletir e o agir de seus sujeitos endereçados ao mundo a ser transformado e humanizado, não pode reduzir-se a um ato de depositar ideias de um sujeito no outro, nem tampouco tornar-se simples troca de ideias a serem consumidas pelos permutantes. (FREIRE, 2007, p. 91).

Portanto, quanto mais o educador perceber que o diálogo em suas aulas é de suma importância, poderá ter como retorno o maior comprometimento dos alunos, bem como estes poderão estar mais mobilizados a transformarem sua realidade. O educador ao atuar nessa perspectiva torna-se um mediador, capaz de articular as experiências dos alunos com o mundo, levando-os a refletir sobre seu entorno, assumindo, assim, um papel mais humanizador em sua prática docente.

No quadro 4, solicitamos que os educadores descrevessem sobre suas experiências durante o curso através da seguinte questão: descreva alguma experiência, momento e/ou atividade junto aos estudantes que considere significativo.

\begin{tabular}{|c|l|}
\hline Educador & \multicolumn{1}{|c|}{ Resposta } \\
\hline E1 & $\begin{array}{l}\text { Atuei como professor da disciplina de Biologia, na qual explora conteúdos do campo da saúde. } \\
\text { Estes assuntos promoveram intensas discussões e relatos. Explico melhor. Alguns estudantes } \\
\text { possuíam as doenças nas quais eu, enquanto professor, sabia apenas a teoria. Tuberculose, } \\
\text { sífilis, HIV, hepatite e leptospirose, a título de exemplo, faziam parte da realidade, da vivência } \\
\text { deles. Aproveitamos estes momentos, justamente, para ouvir os estudantes, promover um } \\
\text { espaço de troca e aprendizagens, troca de quem leu para quem viveu e vive com certas doenças } \\
\text { e/ou síndromes. Não houve "vitimização" ou mesmo "culpabilização", pelo contrário, } \\
\text { buscamos articular nossos conhecimentos e experiências. Foram momentos como esses que } \\
\text { considero significativos, marcantes e produtivos. }\end{array}$ \\
\hline E2 & $\begin{array}{l}\text { Cada aula que passamos juntos foi significativa. A cada aula aprendíamos coisas novas, } \\
\text { trocávamos experiências, cada aula era perceptiva o crescimento pessoal e intelectual deles. } \\
\text { Isso foi muito significativo. }\end{array}$ \\
\hline E3 & $\begin{array}{l}\text { Perceber o crescimento significativo que a escrita e reescrita de assuntos debatidos em sala de } \\
\text { aula produziu foi uma das maiores alegrias que tive. Os alunos participativos, questionadores, } \\
\text { com reflexões que, por vezes, eu precisava parar e pesquisar, escutar, perguntar. Isso, para } \\
\text { quem é curiosa e tem fome de aprendizagem é um alimento para a alma. } \\
\text { Português: Conseguir desmistificar que português e difícil e que os alunos não sabem o mesmo } \\
\text { e minha principal tarefa enquanto professora. Assistir alunos com olhos brilhantes, com mil } \\
\text { perguntas, e dizer que minha aula foi significativa para eles, não tem preço. }\end{array}$ \\
\hline $\begin{array}{l}\text { Fizemos um experimento de reação química. Buscávamos analisar e quantificar o pH de } \\
\text { soluções. Tecnicamente era simples, bastava extrato de repolho roxo e soluções como suco de } \\
\text { limão, vinagre, hipoclorito de sódio, iodopovidona e outros. No entanto, o brilho nos olhos } \\
\text { deles e o entusiasmo de perceberem as transformações foi emocionante. Ali eles se sentiram } \\
\text { vivos... sujeitos ativos. Inteligentes. Ademais, tivemos outro dia em que nos paramos a analisar }\end{array}$ \\
\hline E4
\end{tabular}


RELACult - Revista Latino-Americana de Estudos em Cultura e Sociedade

\begin{tabular}{|c|l|}
\hline & $\begin{array}{l}\text { as composições químicas das estrelas... Foi incrível, mergulhamos em uma infinidade de } \\
\text { sonhos e utopias científicas e de ficção. Aprendemos/evoluímos e saímos com dor de tanto } \\
\text { sorrir. }\end{array}$ \\
\hline E5 & $\begin{array}{l}\text { Durante o tempo em que estive trabalhando no curso, não vivenciei nenhuma atividade } \\
\text { específica com eles, mas percebo que as oficinas que eles participaram, como a do corpo } \\
\text { humano os motivaram para seguirem nos estudos. Eles comentavam em aula as atividades. }\end{array}$ \\
\hline
\end{tabular}

Quadro 4 - Respostas da questão 3

Fonte: Autores (2018)

Os educadores quando questionados sobre alguma experiência que foi marcante tanto para eles quanto para os estudantes, destacam, a grande maioria, uma atividade específica de sua disciplina. Porém percebemos que ao desenvolverem momentos em que os alunos construíam e manuseavam o material, estes se envolviam e produziam a partir de seus conhecimentos novos saberes. Registramos a partir das respostas dos educadores que durante as aulas os alunos tinham um espaço para dialogarem e mostrarem sua bagagem pessoal sobre os temas trabalhados. Nesse sentido, Silva e Zanon (2000) dizem que: "a escola deve ser o local de mediação entre a teoria e a prática, o científico e o cotidiano [...] levar em conta aspectos regionais e se aproximar da comunidade onde está inserida”.

Embora o Cultura da Paz não se caracterize como uma escola, mas sim como um curso pré-universitário popular, a relação entre educadores e educandos se estabeleceu de forma próxima, com realização de atividades que estão para além do modelo tradicional dos cursos preparatórios realizados pelos estudantes brasileiros. A realidade dos estudantes foi, como pode ser percebido na resposta do E1 e E2, substrato para o desenvolvimento das aulas. Tanto se fala e escreve, na seara educacional, sobre contextualização e aproximação da realidade dos estudantes com os conteúdos a serem trabalhados e, nesse contexto, vemos se concretizar esta prerrogativa no curso Cultura da Paz.

Ademais, torna-se importante sublinhar que a palavra "significativo" foi recorrente nas respostas dos educadores investigados. O quadro 4 nos mostra isso. Se olharmos a etimologia da palavra, entenderemos que ela vem do latim significativus, ou seja, que possui significação. O que estamos querendo dizer com isso é que as respostas dos investigados denotam as vivências, ou a atuação dos educadores, de forma relevante, interessante para estes sujeitos de alguma maneira. Mesmo que isso nos aproxime de questões mais subjetivas e de não fácil detalhamento, torna-se, pelo menos para nós, autores, impossível não considerar estes apontamentos.

\section{Conclusões}


O crescimento da população prisional é um alarmante, ainda mais quando percebe-se que há uma tríade que caracteriza as pessoas presas: pobres, negros e com baixa escolaridade. Essas pessoas que estão institucionalizadas nas prisões não ficarão toda a sua vida presas, e que ao saírem do sistema prisional o baixo nível educacional e de escolarização acarretam na diminuição de oportunidade no mercado de trabalho. Pensando nisso, entendemos como relevante projetos como este, que foquem na educação prisional como sendo um caminho possível para a ressocialização das pessoas presas ao convívio extramuros.

A educação opera como fator de relevância para a vida das pessoas presas. Potencializa o resgate social dos indivíduos, proporcionando maior "autonomia" e minimização da discriminação social, auxiliando para a construção e reconstrução do presente que irá proporcionar impactos para a vida além do cumprimento da sentença jurídica. Desta forma, o Curso Cultura para a Paz durante o período que teve suas atividades desenvolvidas, visava através da educação proporcionar para os seus alunos novos olhares sobre as mais diversas realidades dos mesmos.

Por meio das análises que fizemos podemos concluir que os educadores têm preocupação, dedicação e compreensão de que a educação é uma possibilidade de crescimento pessoal, e social das pessoas que estão cumprindo pena prisional. Pois, o momento presente em que os detentos se encontram não será definitivo para as suas vidas. Por isso, proporcionar acesso ao crescimento educacional é possibilitar novas escritas de histórias de vida para os detentos no pressente e que reverbere até o futuro.

\section{Referências}

AGUIAR, A. Educação de Jovens e Adultos privados de liberdade: perspectivas e desafios. Paidéia r. do cur. de ped. da Fac. de Ci. Hum. e Soc. v. 1, n. 6, p. 101-121, jul./dez. 2009. Disponível em: http://www.fumec.br/revistas/paideia/article/view/953/725. Acesso em: 08 out. 2017.

BRASIL; Lei N ${ }^{\circ}$ 7.210, de 11 de Julho de 1984. Lei das Execuções Penais-LEP. Disponível em: http://www.planalto.gov.br/ccivil_03/leis/L7210.htm. Acesso em: 14 setembro 2018.

BRASIL, Portal Brasil. 2012. Levantamento mostra escolaridade dos presidiários no País. Disponível em: http://www.brasil.gov.br/educacao/2012/04/levantamento mostraescolaridade-dos-presidiarios-no-pais. Acesso em: 14 setembro 2018.

BRASIL, Constituição da República Federativa do Brasil de 1988.

BRASILIA, Ministério da Justiça e Segurança Pública. Departamento Penitenciário Nacional, 2014 Levantamento de Informações penitenciárias (INFOPEN). Disponível em: 
http://www.justica.gov.br/news/mj-divulgara-novo-relatorio-do-infopen-nesta-tercafeira/relatorio-depen-versao-web.pdf. Acessado em: 14 setembro 2018.

BRASILIA, Ministério da Justiça e Segurança Pública. Departamento Penitenciário Nacional, 2017 Levantamento de Informações penitenciárias (INFOPEN). Disponível em: http://www.justica.gov.br/news/ha-726-712-pessoas-presas-nobrasil/relatorio_2016_junho.pdf. Acesso em: 14 setembro 2018.

FREIRE, Paulo. Pedagogia da autonomia: saberes necessários à prática educativa. São Paulo: Paz e Terra, 2007. 144 p.

SARTRE, J.P. O existencialismo é um humanismo. São Paulo: Abril, 1978. 88 p.

SILVA, L. H. A. \& Zanon, L. B. A experimentação no ensino de ciências. In Aragão, R. M. R. \& Schnetzler, R. P. (Org.). Ensino de ciências: fundamentos e abordagens. Piracicaba: UNIMEP/CAPES, 2000. p.120-153. 